\title{
Prevalence of Iron Deficiency Anemia and Determinants among Pregnant Women Attending Antenatal Care at Woldia Hospital, Ethiopia
}

\section{Tsegahun Worku Brhanie ${ }^{1 *}$ and Habtamu Sisay ${ }^{2}$}

${ }^{1}$ Department of Applied Human Nutrition, Bahir Dar University, Ethiopia

${ }^{2}$ Woldia Hospital, Ethiopia

\begin{abstract}
Background: Anemia is one of the most widespread public health problems, especially in developing countries. It impaired cognitive development, reduced physical work capacity and in severe cases increased risk of mortality particularly during prenatal period. Anemia in pregnant women is defined by low hemoglobin levels, below $11 \mathrm{~g} / \mathrm{dL}$ in $1 \mathrm{st}$ and $3 \mathrm{rd}$ trimester and less than $10.5 \mathrm{~g} / \mathrm{dl} 2$ nd trimester. The objective of this study is to assess prevalence of iron deficiency anemia in pregnant women at Woldia general hospital.
\end{abstract}

Method: This was a cross-sectional study conducted within a five month period at Woldia General Hospital.

Results: Out of 243 women enrolled in the study, ninety five (39.1\%) were found to be anemic. Anemia was more prevalent in the first $(52.2 \%)$ and second $(52.6 \%)$ trimesters. nine women $(9.5 \%)$ had severe anemia, and 86 women $(90.5 \%)$ had mild anemia. Association with previous antenatal care follow up, the pregnant women who has history of ANC follow up in previous pregnancy has low prevalence $(48.2 \%)$ whereas those who did not have antenatal care follow up previously have high prevalence (94.4\%).

Conclusion: Prevalence of anemia is high in the study area and determined by different factors like feeding habit, level of education and history of antenatal care follow up. Based on this finding we recommend that; iron supplementation should be encouraged as a prophylactic measure. Health education for women on antenatal care follow up and diversified feeding practice should be given for the reduction of anemia.

Keywords: Sever anemia; Mild anemia; Iron; Efficiency

\section{Introduction}

Anemia is one of the most widespread public health problems, especially in developing countries. It impaired cognitive development, reduced physical work capacity and in severe cases increased risk of mortality particularly during prenatal period [1].

Anemia in pregnant women is defined by hemoglobin levels less than $11 \mathrm{~g} / \mathrm{dl}$ forlstand $3^{\text {rd }}$ trimester and $10.5 \mathrm{~g} / \mathrm{dl}$ for $2^{\text {nd }}$ trimester. It is usually caused by iron deficiency, which is the most common nutrient deficiency in the world. It has been estimated that, at any one time in developing countries, half of the population (mainly children and women of reproductive age) is affected by anemia [2]. During pregnancy, approximately $75 \%$ of all anemia diagnosed are due to iron deficiency [3].

Iron deficiency is highest in population sub groups that are peak rates of growth namely infants, young children and pregnant women. Pregnancy is the time which risk developing iron deficiency anemia is greatest as iron requirements are substantially higher than 4-5 times than the non-pregnant [4]. Furthermore, WHO considers that women in developing countries may be pregnant for as much as one half of their reproductive lives and therefore are at increased risk of anemia during this time.

In the developing world, young pregnant women, and their infants and children frequently experience a cyclic under nutrition (macro nutrient and micronutrient) and repeated infection including parasitic infections. This lead to adverse consequences that can continue from one generation to the next. Among parasitic infections, malaria and intestinal helminthes co-exist widely with micro nutrient deficiencies and contribute importantly to anemia and this resulted for growth retardation and under development [5-9].

\section{Statement of purpose}

Anemia is remaining a major public-health problem in many developing country affecting about a quarter of the world's population and its adverse health consequences are affecting people of different groups with varied degree of affluence. Among these population groups, women of childbearing age (15-49 years) and children are highly vulnerable by the problem.

Identifying the magnitude of anemia and its determinants in highrisk groups, such as women of child bearing age, would be essential for evidence-based intervention modalities. Particularly in developing countries, like Ethiopia, where the social conditions pose serious challenges to women [10]. The nutritional status of women in Ethiopia, as in other developing countries, is low, and their daily workload is often enormous because of reproducing and ensuring the survival of their children [11]. To improve the nutrition situation of Ethiopian women, there have been several interventions by the Ministry of Health through its Essential Nutrition Action (ENA) plan, comprising the supplementation of three major nutrients (vitamin A, iron, and iodine) and other promoting activities, such as exclusive breastfeeding,

*Corresponding author: Tsegahun Worku Brhanie, Department of Applied Human Nutrition, Bahir Dar University, Ethiopia, Tel: +251918041869; E-mail: tsegahunw73@gmail.com

Received August 24, 2016; Accepted December 06, 2016; Published December 13,2016

Citation: Brhanie TW, Sisay H (2016) Prevalence of Iron Deficiency Anemia and Determinants among Pregnant Women Attending Antenatal Care at Woldia Hospital, Ethiopia. J Nutr Disorders Ther 6: 201. doi: 10.4172/2161- 0509.1000201

Copyright: (C) 2016 Brhanie TW, et al. This is an open-access article distributed under the terms of the Creative Commons Attribution License, which permits unrestricted use, distribution, and reproduction in any medium, provided the original author and source are credited. 
appropriate complementary feeding, and improved maternal and child nutrition [12-15].

Studying this research is important to know the prevalence and identify factors contribute to iron deficiency anemia in pregnant women such as poor nutritional diet, poor antenatal care service and inadequate iron supplementation contribute to anemia in pregnant women. In addition to that other factors like nutrition and sociodemographic situation contribute to anemia during pregnancy [16]. There is no updated data about the prevalence of iron deficiency anemia in pregnant women at the study area. This research is used to guide the ANC service to work towards alleviating the problem with an appropriate care and treatment, this study will use as base line data to the intervention provided in the health facility $[17,18]$.

\section{Methods}

\section{Study setting and study period}

The study carried out at Woldia General Hospital. It is one of the Government hospitals in Ethiopia which established in 1953 E.C by American missionary [19-21]. It is located in the northern part of Amhara regional state in the capital town of north wollo zone, Woldia. Woldia found in Amhara regional state located at about $360 \mathrm{~km}$ to the north east of the regional capital town Bahir Dar and $521 \mathrm{~km}$ from Addia Abeba. The town has altitude of $11^{\circ} 50^{\prime} 39^{\circ} 36 / \mathrm{E} 11.833^{\circ} \mathrm{N}$ and elevation of 2112 meter above sea level [22-25]. Based on the 2007 national census conducted by the Central Statistical Agency of Ethiopia (CSA), woldia has a total population of 46,139 , of whom 23,000 are men and 23,139 women [26,27] and it has five Kebeles. Woldya has 1 hospital, 2 health center and more than nine private clinics. The study was conducted from January to May 2016 at Woldia General Hospital.

\section{Study design}

A cross sectional study was used to assess prevalence of anemia in pregnant mothers attending ANC at Woldia General Hospital.

\section{Sample size determination}

The required sample size for this study was calculate based on the prevalence rate of (19.7\%) anemia in pregnant women at mekelle town of Tigray region, Ethiopia from literature review, the $95 \%$ confidence interval and 5\% marginal error, sample size (n) the formula shown below was used to determine the sample size.

$\mathrm{n}=\mathrm{Z}^{2} \mathrm{P}(1-\mathrm{P}) / \mathrm{D}^{2}$

Where,

$\mathrm{D}=$ margin of error between the sample and the population

$\mathrm{n}=$ sample size

$Z=95 \%$ confident interval

$\mathrm{P}=$ prevalence rate of $19.7 \%$ based on the previous study at Mekelle, Tigray

$\mathrm{n}=(1.96)^{2} \times 0.197(1-0.197) / 243=0.05^{2}$

\section{Sampling procedure}

Fisher's formula for estimating means and proportions was used to determine the sample size.

\section{Data collection instruments/tools and procedures}

A structured questionnaire was used to obtain socio-demographic information, present and past history in pregnant women, and dietary habit.

The questionnaire was developed in English and it translated to Amharic language. The entire principal investigator was responsible for conducting all interviews and the questioners were examined for clarity ambiguity time taken to fill it out and analyze ability. Appropriate adjustments were then made.

The study participants were identified as follows: After clients received the routine ANC services, the interviewer informed the clients about the study, its objectives, risks and benefits and then the interviewer convince the client to complete the interview. Medical records were examined and the patients interviewed in a private study room. The interviews were conducted in a safe, secure and confidential environment and then the hemoglobin test result obtained from the current client history card.

\section{Data processing and analysis}

Quantitative data was coded and entered in to Epi info version 3.5.1 software and the data was transferred to SPSS version 16. Descriptive analysis like mean, frequency and percentage were calculated.

The research was approved by the Ethical Clearance Committee of Bahir dar University. Permission letter was submitted to woldia general hospital. Confidentiality was ensured by making the questionnaires anonymous. Personal identification of the respondents was not asked and the interview also conducted in safe and private place. They were also be assured that the information provided whether orally or in writing would be used only for research purpose and would therefore be strictly anonymous and data will be entered as confidential, anonymous, aggregate analysis and reporting system will put secured and in place.

\section{Result}

\section{Overall baseline characteristics of study population}

A total of two hundred forty three (243) pregnant mothers who were attending antenatal care were enrolled in the study. $45.7 \%$ (111) of them were primigravida and the majority of them were womens of age between 21 to 30 years at $67.5 \%$ (164). 8.2\% mothers were illitrate, $8.6 \%$ also attended colleage and unversty. Three fourth of pregnant mothers were married (79.1\%) (192), 5.3\% and 15.6\% are categorized under single and other. The higest number of the study population were housewife $(67.0 \%)$ and followed by other category and murchant $13.6 \%$ and $11.1 \%$ respectivly. where as these and other related datas are showen in Table 1 below.

Among mothers who were encluded in this study, 150 (64.1\%) eat meat and animal products less frequently as every week or less. Besides this $3.7 \%$ of mothers did not eat meat and animal product in their pregnancy time. Majority of the mothers teke iron supplementation for one month (44.0\%) when compered from 30-60 days and 60-90 days as $38.7 \%$, and 16.25 respectivly. For these and other food intake habits and supplementation taken showen in Table 2 below.

One hundred and thirty two pregnant mothers were their second and more pregnancies. 16 pregnant mother $(21.1 \%)$ exhibted excessive blood loss from their last pregnancy. $56.1 \%$ of women do not have ANC follow up during their last pregnancy and therest $43.9 \%$ have ANC follow up before. $70.5 \%$ of women who enroled in this study have barth spacing more than two years and the rest are two years and less (Table 3). 
Citation: Brhanie TW, Sisay H (2016) Prevalence of Iron Deficiency Anemia and Determinants among Pregnant Women Attending Antenatal Care at Woldia Hospital, Ethiopia. J Nutr Disorders Ther 6: 201. doi: 10.4172/2161- 0509.1000201

Page 3 of 6

\begin{tabular}{|c|c|c|}
\hline Characteristics & Number & Percentage (\%) \\
\hline \multicolumn{3}{|l|}{ Sociodemographic } \\
\hline Age (in year): $15-20$ & 30 & 13.3 \\
\hline $21-30$ & 164 & 67.5 \\
\hline$>30$ & 49 & 20.2 \\
\hline \multicolumn{3}{|l|}{ Religion } \\
\hline Christian & 141 & 38 \\
\hline Muslim & 102 & 41.9 \\
\hline Other & 0 & 0 \\
\hline \multicolumn{3}{|l|}{ Educational status } \\
\hline Illiterate & 20 & 8.2 \\
\hline Read and write & 45 & 18.5 \\
\hline Grade 1-8 & 92 & 37.8 \\
\hline Grade 9-12 & 65 & 26.7 \\
\hline College and University & 21 & 8.6 \\
\hline \multicolumn{3}{|l|}{ Marital status } \\
\hline Married & 192 & 79 \\
\hline Single & 13 & 5.3 \\
\hline Other & 38 & 15.6 \\
\hline \multicolumn{3}{|l|}{ Occupation } \\
\hline Farmer & 20 & 8.2 \\
\hline Housewife & 163 & 67 \\
\hline Merchant & 27 & 11.1 \\
\hline Other & 33 & 13.6 \\
\hline \multicolumn{3}{|l|}{ Parity } \\
\hline Primigravida & 111 & 45.7 \\
\hline Multiggravida & 92 & 37.8 \\
\hline Grandmuligravida & 40 & 16.5 \\
\hline \multicolumn{3}{|l|}{ Gestational age } \\
\hline First trimester & 23 & 9.5 \\
\hline Second trimester & 147 & 60.5 \\
\hline Third trimester & 73 & 30 \\
\hline
\end{tabular}

Table 1: Socio-demographic and reproductive characteristics of study population.

\begin{tabular}{|c|c|c|}
\hline Parameter & Number & Percentage (\%) \\
\hline \multicolumn{3}{|c|}{ Consumption of meat and animal product during the recent pregnancy } \\
\hline Consumed & 9 & 3.7 \\
\hline Not consumed & 234 & 96.2 \\
\hline \multicolumn{3}{|c|}{ Level of consumption of meat and animal product } \\
\hline Every day & 21 & 8.9 \\
\hline Every two days & 63 & 26.9 \\
\hline Every week or less & 150 & 64.1 \\
\hline \multicolumn{3}{|c|}{ Consumption of green leafy vegetables and fruits } \\
\hline Consumed & 0 & 0 \\
\hline No consumed & 243 & 100 \\
\hline \multicolumn{3}{|c|}{ Level of consumption of green vegetables and fruits } \\
\hline Every day & 9 & 3.7 \\
\hline Every two days & 93 & 38.3 \\
\hline Every week or le & 141 & 58 \\
\hline \multicolumn{3}{|c|}{ Consumption of tea/coffee immediately after meal } \\
\hline Consumed & 36 & 34.6 \\
\hline Not consumed & 59 & 42.5 \\
\hline \multicolumn{3}{|c|}{ Do you take iron supplementation in this ANC period } \\
\hline Yes & 204 & 83.9 \\
\hline No & 39 & 16.1 \\
\hline \multicolumn{3}{|c|}{ Level of supplement taken } \\
\hline$<30$ days & 92 & 44 \\
\hline $30-60$ days & 79 & 38.7 \\
\hline $60-90$ days & 33 & 16.2 \\
\hline
\end{tabular}

Table 2: Diatary habits and other factors included in the study.

\begin{tabular}{|c|c|c|}
\hline Determinant characterstics $(n=132)$ & Number & $\%$ \\
\hline \multicolumn{3}{|c|}{ Is there excessive blood loss during previous delivery } \\
\hline Yes & 16 & 12.1 \\
\hline No & 116 & 87.9 \\
\hline \multicolumn{3}{|c|}{ Did you have ANC follow up in the previous pregnancy } \\
\hline Yes & 58 & 43.9 \\
\hline No & 74 & 56.1 \\
\hline \multicolumn{3}{|l|}{ Was any abortion committed before } \\
\hline Yes & 15 & 14.3 \\
\hline No & 117 & 88.6 \\
\hline \multicolumn{3}{|l|}{ Level of birth spacing by the mothers } \\
\hline$<2$ years & 39 & 29.5 \\
\hline$>2$ years & 93 & 70.5 \\
\hline
\end{tabular}

Table 3: Maternal blood loss and related issue.

\begin{tabular}{|l|c|c|}
\hline Parameter & Number & $\%$ \\
\hline Overall prevelance of anemia $\mathbf{n = 2 4 3}$ & 39.1 \\
\hline Anemia & 95 & 60.9 \\
\hline No anemia & 148 & 90.5 \\
\hline Severity of anemia $\mathbf{n = 9 5}$ & 86 & 9.5 \\
\hline Mild & 9 & \\
\hline Sever & \multicolumn{2}{|l|}{} \\
\hline
\end{tabular}

Table 4: Prevalence of anemia in Woldia general hospital.

Overall prevalence of anemia among antenatal women attending clinic at Woldia general hospital

In Table 4 below shows that among 243 pregnant mothers who attended ANC visit in Woldia General Hospital 39.1\% (95 mother) were anemic based on their hemoglobin test result $(\mathrm{Hb}<11.1 \mathrm{~g} / \mathrm{dl})$ and the rest 148 (60.9\%) did not show iron deficiancy anemia ( $\mathrm{Hb}>11.1 \mathrm{~g} /$ dl). Hence, the overall prevalence of anemia among mothers attending ANC clinic at Woldia general Hospital was $39.1 \%$ (95). Eighty six women (90.5\%) had mild anemia ( $\mathrm{Hb} 11.1-8 \mathrm{~g} / \mathrm{dl})$, and nine mothers (9.5\%) had sever anemia $(\mathrm{Hb}<7 \mathrm{~g} / \mathrm{dl})$.

Prevalence of iron deficiancy anemia in relation to reproductive and socio-demographic characteristics among pregnant mothers at Woldia general hospital

Anemia was found to be more prevalent in women aged between 21-30 years at $44.5 \%$ as compared to $20.0 \%$ in the age $15-20$ years of age group and $32.7 \%$ in the above thirty age group. Mothers who had schooling grade 1-8 were taking the higest coverage $37.8 \%$ and $8.2 \%$ illitrate, $18.5 \%$ were mothers who can read and write only. Only $8.6 \%$ of mothers attend college and universty.

There were as many housewife as were merchant in this study (67.0\% and $11.1 \%$ respectively). Anemia was found to be more prevalent in those who were farmers at $55.0 \%$ as compared to those who were housewife and merchant (35.6\% and $29.6 \%$ respectively) However, level of work and knowladge has the most significant relation with the prevalance of Anemia (Table 5).

Prevalence of anemia in relation to reproductive characteristics

$90.5 \%$ of all the women in this study initiated antenatal visits in their second or third trimesters, with only $9.5 \%$ coming in their first trimester. Majority of the women were visited in their second trimester $(60.5 \%)$ and $30.04 \%$ in their third trimester. 
Citation: Brhanie TW, Sisay H (2016) Prevalence of Iron Deficiency Anemia and Determinants among Pregnant Women Attending Antenatal Care at Woldia Hospital, Ethiopia. J Nutr Disorders Ther 6: 201. doi: 10.4172/2161- 0509.1000201

Page 4 of 6

\begin{tabular}{|c|c|c|c|}
\hline \multirow{3}{*}{$\begin{array}{l}\text { Socio Demographic } \\
\text { Characteristics }\end{array}$} & \multicolumn{3}{|c|}{ Anemia } \\
\hline & \multirow{2}{*}{$\begin{array}{c}\text { Yes } \\
\text { Number/\% }\end{array}$} & \multirow{2}{*}{$\begin{array}{c}\text { No } \\
\text { Number/\% }\end{array}$} & \multirow{2}{*}{ Total } \\
\hline & & & \\
\hline \multicolumn{4}{|l|}{ Age } \\
\hline $15-20$ & $6(20.0)$ & $24(80)$ & 30 \\
\hline $21-30$ & $73(44.5)$ & $91(55.5)$ & 164 \\
\hline$>30$ & $16(32.7)$ & $33(67.3)$ & 49 \\
\hline \multicolumn{4}{|l|}{ Educational status } \\
\hline Illiterate & $12(60.0)$ & $8(40)$ & 20 \\
\hline Read and write & $23(51.1)$ & $22(48.9)$ & 45 \\
\hline Grade 1-8 & $34(36.9)$ & $58(63.1)$ & 92 \\
\hline Grade 9-12 & $21(32.3)$ & $44(67.7)$ & 65 \\
\hline College and University & $5(23.8)$ & $16(76.2)$ & 21 \\
\hline \multicolumn{4}{|l|}{ Marital status } \\
\hline Married & $78(40.6)$ & $114(59.4)$ & 192 \\
\hline Single & $4(30.8)$ & $9(69.2)$ & 13 \\
\hline Other & $13(34.2)$ & $25(65.8)$ & 38 \\
\hline \multicolumn{4}{|l|}{ Occupation } \\
\hline Farmer & $11(55.0)$ & $9(45.0)$ & 20 \\
\hline Housewife & $63(38.7)$ & $100(61.3)$ & 163 \\
\hline Merchant & $8(29.6)$ & $19(69.4)$ & 27 \\
\hline Other & $13(39.4)$ & $20(59.6)$ & 33 \\
\hline
\end{tabular}

Table 5: Prevalance of anemia in relation to socio-demographic characteristics of antenatal mothers at Woldia General Hospital.

The highest percentage of women with anemia was noted in the first trimester at $52.2 \%$, followed by the second trimester at $43.5 \%$. Only $26.03 \%$ of the women in their third trimester had anemia.

The highest percentage of anemia was found in the grandmultigravida (45.0\%) as compared to $34.2 \%$ and $42.4 \%$ for the primigravidae and multigravida respectively. As the data shows that as the parrti increases the prevalence of Anemia also increases (Table 6).

The prevalence of Anemia in pregnant women who did not consume meat and animal products are higher than the mothers who did consume $44.4 \%$ and $38.9 \%$ respectivly. The higest prevalance of anemia (50\%) were found in pregnant women who eat meat and animal product weekly or less. The pregnant women who eat meat and animal products every day and every two days has the lowest prevalence for anemia, 14.2 and 26.9 respectivly.

All of the pregnant women at ANC consumed green leaf vegetables and frutes in different consumption patern. Mothers whom they eat green leaf vegetable less regularly have high prevalence of iron deficiancy anemiya (51.7\%) than mothers who eat daily and every two days $11.1 \%$, and $22.6 \%$ respectivly (Table 7 ).

Anemia privalence has relation with privious excessive blood loss $87.5 \%$ than women that not have history of excessive blood loss in the lase delivery $(69.8 \%)$. On the other hand pregnat mother who attended ANC at the previous pregnancy has less prevalence rete $48.2 \%$ than the mother who do not have history of ANC attendance in the previous pregnancy $(94.4 \%)$.

\section{Discussion}

Anemia in pregnancy is one of the most widespread public health problems especially in developing countries and has important health and welfare, social and economic consequences.

Anemia in pregnancy increase in overall risk of maternal death related to pregnancy and delivery. Non-fatal maternal complications during antenatal period includes: poor weight gain, preterm labors, pregnancy induced hypertension, placenta previa, accidental hemorrhage, eclampsia, premature rupture of membranes and increased susceptibility to infections like urinary tract infections. Plus to that this problem has largest effect on the fetus welfare and proper development. These complications include prematurity, low birth weight, low APGAR scores, fetal mental impairment and infant deaths.

The prevalence of anemia as seen in this study $39.1 \%$, is an indication that anemia during pregnancy is still a major problem in Ethiopia (Table 5). More than one third of pregnant women were found to be anemic. This prevalence is higher than what was in the study on Ethiopian women from June to July 2005 and a study conducted on Mekele Ethiopia prevalence of $30.4 \%$ and $19.7 \%$ respectively [22,24]. The variance could be attributed to differences between urban and rural prevalence probably as a result of diet differences. The other study

\begin{tabular}{|c|c|c|c|}
\hline \multirow{2}{*}{ Reproductive characteristic } & \multicolumn{3}{|c|}{ Anemia } \\
\cline { 2 - 3 } & Yes & No & \multirow{2}{*}{ Total } \\
\cline { 2 - 3 } & Number \% & Number \% & \\
\hline Parity & $38(34.2)$ & $73(65.8)$ & 111 \\
\hline Primigravida & $39(42.4)$ & $53(57.6)$ & 92 \\
\hline Multiggravida & $18(45.0)$ & $22(55.0)$ & 40 \\
\hline Grandmultigravida & & & \\
\hline Gestational age & $12(52.2)$ & $11(47.8)$ & 23 \\
\hline First trimester (0-13 week) & $64(43.5)$ & $83(56.5)$ & 147 \\
\hline Second trimester (14-27 week) & $19(26.0)$ & $54(74.0)$ & 73 \\
\hline Third trimester (>28 week) & $19(28)$ \\
\hline
\end{tabular}

Table 6: Prevalence of anemia in relation to reproductive characteristics among antenatal mothers at Woldia General Hospital.

\begin{tabular}{|l|c|c|c|}
\hline \multirow{2}{*}{ Parameter $(\mathbf{n}=243)$} & \multicolumn{3}{|c|}{ Anemia } \\
\cline { 2 - 3 } & Yes & No & \multirow{2}{*}{ Total } \\
\cline { 2 - 3 } & Number \% & Number \% & \\
\hline
\end{tabular}

Consumption of meat and animal product during the recent pregnancy

\begin{tabular}{|l|c|c|c|}
\hline Consumed & $91(38.9)$ & $143(61.1)$ & 234 \\
\hline Not consumed & $4(44.4)$ & $5(55.6)$ & 9
\end{tabular}

Level of consumption of meat and animal product

\begin{tabular}{|l|c|c|c|}
\hline Every day & $3(14.3)$ & $8(85.7)$ & 21 \\
\hline Every two days & $17(26.9)$ & $46(73.1)$ & 63 \\
\hline Every week or less & $75(50.0)$ & $75(50.0)$ & 150 \\
\hline
\end{tabular}

Consumption of green leaf vegetables and fruits

Consumption of green leaf vegetables and fruits
\begin{tabular}{|l|c|c|c|}
\hline Consumed & $95(39.1)$ & $148(59.9)$ & 243 \\
\hline No consumed & 0 & 0 & 0 \\
\hline Level of Consumption of green leafy vegetables and fruits \\
\hline Every day & $1(11.1)$ & $8(89.9)$ & 9 \\
\hline Every two days & $21(22.6)$ & $72(77.4)$ & 93 \\
\hline Every week & $73(51.8)$ & $68(48.2)$ & 141 \\
\hline
\end{tabular}

Consumption of tea/coffee immediately after meal

\begin{tabular}{|l|l|l|l|}
\hline Consumed & $59(42.5)$ & $80(57.5)$ & 139 \\
\hline Not consumed & $36(34.6)$ & $68(65.4)$ & 104
\end{tabular}

Do you take iron supplementation in this ANC period

\begin{tabular}{|c|c|c|c|}
\hline Yes & $66(32.4)$ & $138(67.6)$ & 204 \\
\hline No & $29(74.3)$ & $10(25.7)$ & 39 \\
\hline \multicolumn{4}{|c|}{ Level of supplement taken } \\
\hline$<30$ days & $34(80.9)$ & $58(19.1)$ & 92 \\
\hline $30-60$ days & 53 (67.9) & 26 (32.1) & 79 \\
\hline $60-90$ days & $8(24.3)$ & $25(74.7)$ & 33 \\
\hline
\end{tabular}

Table 7: Prevalence of anemia in relation to dietary characteristics among antenatal mothers at Woldia General Hospital. 
conducted in the westeren Ethiopia, Jimma (WHO 1993) [21]. The prevalence of anemia in pregnancy were $57 \%$ this difference would be the geographical location and the differene of the feeding habiite and related factors.

Level of education and the employment situation has a relation with the anemia, as the result indcates that $60 \%$ of the illitrate were anemic when compered to the mothers who are of grade 9-12 and those attend college and Universty (32.3\% and $23.8 \%$ respectively). Even though there are womens who are anemic even they have better acess to education, the level of knowladege and educational status were the better indicator to improve the problem.

The prevalence of Anemia were high in age groupm of 21-30 years (44.5\%), education statuse of non educated (illitrate) at $60 \%$. Whereas the parti grandmulti parti were highly succeptable to anemia (45.0\%) than the primi and multi ( $34.2 \%$ and $42.4 \%$ respectivly).

Feeding habit of the pregnant women were knowen as one factor per the prevalence of anemia in pregnancy $[22,23]$ was also found to be signifiicant factor for the study as there consumption of meat and animal product increases the prevalence of anemia also decreases, women who were eating meat and animal products every day has less prevalence $(14.3 \%)$ than those were eating every two days and weekly or less as $26.9 \%$ and $50 \%$ respectivly.

Cofee and tea consumption immidetly after meal could reduce the iron absorbation in the gastrointestinal sytsem and this could increase the prevalence of anemia. This research also confirmes this idea properly among the anemic women who were enroled in this research $42.5 \%$ were consuming coffee or tea immidetly after meal. However consumpption of coffee or tea immidiatly only will not be the majore factor but the the iron content of the consumed food wellbe the factor (Table 8).

Excessive blood loss in the previous delivery and ANC attendant history of the last pregnancy were important determinant to identify the prevalence of anemia secondery to the previous factors. Hence mothers who were manufested excessive blood loss previous delivery exhibited high perivalence of anemia in the recent pregnancy $(87.5 \%)$. ANC attendant history inthe privious pregnancy were the other factor that determines the prevalence of Anemia in the recent pregnancy i.e., the prevalence of anemia on those who were not attended ANC in the previous pregnancy were registered higer $(94.4 \%)$ than were they attend (45.2\%) (Table 8).

\begin{tabular}{|c|c|c|c|}
\hline \multirow{3}{*}{$\begin{array}{l}\text { Determinants } \\
(n=132)\end{array}$} & \multicolumn{3}{|c|}{ Anemia } \\
\hline & \multirow{2}{*}{$\begin{array}{c}\text { Yes } \\
\text { Number \% }\end{array}$} & \multirow{2}{*}{$\begin{array}{c}\text { No } \\
\text { Number \% }\end{array}$} & \multirow{2}{*}{ Total } \\
\hline & & & \\
\hline \multicolumn{4}{|c|}{ Excessive blood loss in the previous pregnancy } \\
\hline Yes & $14(87.5)$ & $2(12.5)$ & 16 \\
\hline No & $81(69.8)$ & $35(30.2)$ & 116 \\
\hline \multicolumn{4}{|c|}{ Previous ANC follow up } \\
\hline Yes & $27(48.2)$ & $29(51.8)$ & 56 \\
\hline No & $68(94.4)$ & $4(5.6)$ & 72 \\
\hline \multicolumn{4}{|c|}{ Was any abortion previously } \\
\hline Yes & $9(60.0)$ & $6(40.0)$ & 15 \\
\hline No & $86(73.5)$ & $31(26.5)$ & 117 \\
\hline \multicolumn{4}{|c|}{ At what interval did your birth spacing } \\
\hline$<2$ years & $29(74.4)$ & $10(25.6)$ & 39 \\
\hline$>2$ years & $66(70.9)$ & $27(29.1)$ & 93 \\
\hline
\end{tabular}

Table 8: Prevalence of anemia in relation to previous blood loss and other.

\section{Conclusion}

This study shows that anemia in pregnancy is still a significant problem whereby more than one third of the women attending antenatal care were found to be anemic. Then majore cause of this high prevalence is that the food consumption habit (unable to feed varity of food), educational level; of the mother, in approprate iron supplementation taken and others. Birth spacing and multipariti also the other factors that has great contribution to the prevalence of anemia.

There is also need for improvement of diagnostic ability of anemia by the health workers. Routine iron supplementation should be encouraged as prophylactic measure. Other interventional measures and programs to educate the mothers on the need to initiate antenatal care early should be instituted. Health education talks on nutrition needs for the mother and the growing fetus should also be carried out.

\section{Acknowledgment}

First of all we would like to acknowledge Bahir Dar University which gives us this opportunity to do this research. We would like to heart fully to Woldia General Hospital $\mathrm{MCH}$ department staff for their great patient and kind full cooperation to complete the data collection properly.

\section{Reference}

1. http://www.who.int/nutrition/publications/micronutrients/anaemia iron deficiency/WHO_NHD_01.3/en/

2. Hercberg S, Galan P (1992) Nutritional anaemia baillieres. Clin Haematol 5 143-168.

3. Hotez P, Bethony J, Bottazzi E, Brooker S, Buss P (2005) Hookworm: "The great infection of mankind". PLoS Med 2: 67.

4. Sifakis S, Pharmackides G (2000) Anaemia in pregnancy. Ann NY Acad Sci 90: $125-136$

5. Zavaleta N, Berlanga R, Lonnerdal B, Brown H (1993) Prevalence and determinants ofirondeficiencyanaemia in a representative sample of pregnant women in Lima, Peru. Pan American Health Organization.

6. Steketee W (2003) Pregnancy nutrition and parasitic diseases. J Nutr 133 1661-16675.

7. Frewin R, Hensen A, Provan D (1997) ABC of clinical haematology: iron deficiency anaemia. Br Med J 314: 360-363

8. http://apps.who.int/medicinedocs/documents/s21694en/s21694en.pdf

9. Wharton B (1999) Iron deficiency in children: detection and prevention. $\mathrm{Br} J$ Haematol 106: 270-280.

10. Allen LH (2000) Anemia and iron deficiency: effects on pregnancy outcome. Am J Clin Nutr 71: 1280S-1284S

11. Yip R, Ramakrishnan $U$ (2002) Experiences and challenges in developing countries. J Nutr 132: 827S-830S

12. Berhane $Y$, Gossaye $Y$, Emmelin M, Hogberg $H$ (2001) Women's health in rural setting in societal transition in Ethiopia. Soc Sci Med 53: 1525-1539.

13. Gibson MA, Mace R (2006) An energy-saving development initiative increases birth rate and childhood malnutrition in rural Ethiopia. PLoS Med 3: e87.

14. Ethiopia Central Statistical Agency (2006) Ethiopia demographic and health survey 2005: preliminary report. Central Statistical Agency, Addis Ababa. pp: $156-157$.

15. Wolde-Gebriel Z, West CE, Gebru H, Tadesse AS, Fisseha T, et al. (1993) Inter-relationship between vitamin $\mathrm{A}$, iodine, and iron status in schoolchildren in Shoa region, central Ethiopia. Br J Nutr 70: 593-607.

16. Ethiopia Federal Ministry of Health (2004) National guideline for control and prevention of micronutrient deficiencies. Family Health Department, Federal Ministry of Health, Government of Ethiopia, Addis Ababa.

17. Haidar J, Nekatibeb H, Urga K (1999) Iron deficiency anemia in pregnant and lactating mothers in rural Ethiopia. East Afr Med J 76: 618-622. 
Citation: Brhanie TW, Sisay H (2016) Prevalence of Iron Deficiency Anemia and Determinants among Pregnant Women Attending Antenatal Care at Woldia Hospital, Ethiopia. J Nutr Disorders Ther 6: 201. doi: 10.4172/2161- 0509.1000201

18. Haidar J, Muroki NM, Omwega AM, Ayana G (2003) Malnutrition and iron deficiency in lactating women in urban slum communities from Addis Ababa, Ethiopia. East Afr Med 80: 191-194.

19. http://www.unscn.org/layout/modules/resources/files/Policy_paper_No_9.pdf

20. Crompton W (2000) The public health importance of hook worm disease Parasitolog 121: 39-50.

21. Raut BK, Jha MK, Shrestha A, Sah A, Sapkota A, et al. (2014) Prevalence of iron deficiency anemia among pregnant women before iron supplementation in Kathmandu university hospital/Dhulikhel hospital. Journal of Gynecology and Obstetrics 2: 54-58.

22. Desalegn S (1993) Prevalence of anaemia in pregnancy in Jimma town, Southwestern Ethiopia. Ethiop Med J 31: 251-258.
23. Haider $\mathrm{J}$ (2010) Prevalence of anaemia, deficiencies of iron and folic acid and their determinants in Ethiopian women. J Health Popul Nutr 28: 359-368.

24. Kefyalew A, Abdulahi M (2014) Prevalence of Anemia and associated factors among pregnant women in an urban area of eastern Ethiopia 2014: 561567.

25. Abriha (2014) On prevalence and associated factors of anemia among pregnant women in, Mekelle town. BMC Research 7: 888

26. https://en.wikipedia.org/wiki/North_Wollo_Zone

27. Agency CS (2007) The 2007 population and housing census of Ethiopia Central Statistical Agency, Addis Ababa, Ethiopia. 